\title{
Wittgenstein's Tractatus Logico-Philosophicus and a Hierarchical Approach to Solving Logical Paradoxes
}

\author{
VSEVOLOD LADOV \\ Department of Ontology, Cognitive Theory and Social Philosophy, Faculty of Philosophy, Tomsk State University, 36 Lenina Ave., Tomsk, \\ Russia 634050 \\ Laboratory of Logic and Philosophy, Tomsk Scientific Center, Siberian Branch of the Russian Academy of Sciences, 10/4 Akademicheskiy \\ Pr. , Tomsk, Russia 634055
}

Department of Philosophy, Siberian State Medical University, 2 Moskovsky trakt, Tomsk, Russia, 634050

Email: ladov@yandex.ru

\begin{abstract}
The hierarchical approach to the solution of logical paradoxes is considered in the article. The foundations and main theses of the hierarchical approach are analysed through consideration of Russell's theory of types and Tarski's semantic conception. Basic arguments critical of such an approach that have been formulated in logical and epistemological research are presented. A specific characteristic of Wittgenstein's position in the context of the hierarchical approach expressed by him in Tractatus Logico-Philosophicus is identified. The Wittgensteinian version of the hierarchical approach is the most stable in the relation to the critical arguments considered. If we still want to evaluate the hierarchical approach as an acceptable solution to the problem of logical paradoxes, we should employ its Wittgensteinian interpretation, because it is able to overcome the serious critical arguments against the approach presented in contemporary research on logic, epistemology, and the philosophy of mathematics.
\end{abstract}

Keywords: paradoxes, logic, philosophy of mathematics, semantics, theory of types, language, metalanguage, self-reference, hierarchical approach

\section{INTRODUCTION}

Logical paradoxes, for example, the Liar Paradox, were already known in ancient philosophy. Sometimes, considering the Liar Paradox was even risky to the health of ancient thinkers. Sainsbury, one of modern researchers of the problem of paradoxes, describes the Liar Paradox as follows:

'One of the hardest paradoxes to handle is also one of the easiest to state: the Liar paradox. One version of it asks you to consider the man who simply says, "What I am now saying is false." Is what he says true or false? The problem is that if he speaks truly, he is truly saying that what he says is false, so he is speaking falsely; but if he is speaking falsely, then, since this is just what he says he is doing, he must be speaking truly. So if what he says is false, it is true; 
and if it is true, it is false. This paradox is said to have tormented many ancient logicians and caused the premature death of at least one of them, Philetas of Cos'. (Sainsbury 2009: 1).

However, this legendary case with Philetas of Cos is rather an exception to the rule. In most cases, for many centuries, paradoxes were not taken seriously and were considered only unusual logical puzzles. This state of affairs changed only at the beginning of the 20th century, when Bertrand Russell showed that logical paradoxes represent a very serious scientific problem. The foundation of mathematics as one of the most rigorous types of scientific knowledge depends on the solution of this problem, at least in the context of Frege's philosophical program of logicism and mathematical Platonism (Tselitschev 2014; Surovtsev 2016).

The most well-known way of solving logical paradoxes is the hierarchical approach. First, Russell developed the theory of types in which paradoxes were solved at the level of revealing correct forms of thinking (Russell 1908), and then Tarski formulated the semantic conception of metalanguages, in which paradoxes were solved at the level of revealing correct forms of representation of thinking in language (Tarski 1935). The main methodological step used in this hierarchical approach to solving the problem of paradoxes is prohibiting the phenomenon of self-reference. Russell's theory of types regards as logically incorrect such concepts and methods of reasoning the formation of which relies on the phenomenon of self-reference. Tarski's conception of metalanguages forbids mixing the object language and the metalanguage, which itself becomes the object language for the next-level metalanguage. Self-reference in language is possible only when the object language and metalanguage are mixed, and in Tarski's conception, this situation is considered semantically incorrect.

Although the hierarchical approach is still considered the most orthodox way of solving logical paradoxes, it is increasingly criticized in the research literature on logic, epistemology, and the philosophy of mathematics in the last decades of the 20th century and in the early 21st century, in which various shortcomings of Russell's and Tarski's positions are pointed out.

The author of this article draws attention to the special position of Wittgenstein in the context of the hierarchical approach he expressed in paragraphs 3.332 and 3.333 of Logisch-philosophische Abhandlung (Tractatus Logico-Philosophicus) (Wittgenstein 1921). Wittgenstein's position proves to be invulnerable to modern critics of the hierarchical approach. The hierarchical approach can be further considered an acceptable solution of the problem of logical paradoxes but only in its improved, Wittgensteinian, version.

\section{THE FOUNDATIONS OF THE HIERARCHICAL APPROACH TO SOLVING LOGICAL PARADOXES}

Russell considered some paradoxes (contradictions) in his article 'Mathematical Logic as Based on the Theory of Types': the Liar Paradox; the paradox of the class of all classes that are not the members of themselves (Russell's Paradox); the paradox of the relation that subsists between two relations $R$ and $S$ whenever $R$ does not have a relation $R$ to $S$; Berry's Paradox; the paradox of the least indefinable ordinal; Richard's Paradox; and the Burali-Forti Paradox (Russell 1908: 222-224). Russell asserted that the foundation of all paradoxes is the phenomenon of self-reference: 'In all the above contradictions (which are merely selections from an indefinite number) there is a common characteristic, which we may describe as self-reference or reflexiveness' (Russell 1908: 224). In the case of classes, the phenomenon of self-reference appears in the situation when some element of a class is this class itself. In the case of statements, the phenomenon of self-reference appears when the logical subject of a statement is this statement itself. In the formal notation ( $\mathrm{S}$ is $\mathrm{P}$ ) is $\mathrm{P}$. 
The hierarchical approach aims to remove the phenomenon of self-reference as the foundation of paradoxes. It accomplishes this through the elaboration of a consecutive hierarchy of types (levels) of classes, judgments, statements, and sentences.

In accordance with Russell's theory of types, each concrete class may include as elements in itself classes of lower logical types. For each class, it is forbidden to have as elements in themselves classes of different logical types. Each concrete statement may have as its logical subject a statement of one of the lower logical types. A situation in which a statement is a logical subject of the statement itself is not admitted.

In accordance with Tarski's semantic conception, each sentence of a language may speak only about sentences of the objective language for which this sentence is a sentence of the metalanguage. A sentence of the metalanguage may remain a sentence of the objective language for a sentence of the next semantic level formulated on the meta-metalanguage, and so on. Thus, the possibility of the semantically closed language in which one can find the phenomenon of self-reference is foreclosed.

In relation to the specific paradoxes pointed out above, the hierarchical approach works in the following ways:

Russell's Paradox is founded on the phenomenon of self-reference, because the class involving itself is considered here. Accordingly, overcoming the paradox consists in the ban on construction of the class.

The paradox of the relation is founded on the phenomenon of self-reference because the question about the relation of a specific relation to itself may be put here. Accordingly, overcoming the paradox consists in the ban on formulation of the question.

The Burali-Forti Paradox is founded on the phenomenon of self-reference because the concept of the ordinal for series of all ordinals would be formulated when the ordinal itself is included in the series. Accordingly, overcoming the paradox consists in declaring the meaninglessness of the concept.

The Liar Paradox is founded on the phenomenon of self-reference because it is formulated by means of a statement that speaks about itself. Accordingly, overcoming the paradox consists in the ban on formulation of the statement.

Berry's Paradox is founded on the phenomenon of self-reference because a number is discussed that has feature S1 and feature S2, and S2 is the description of feature S1 that contains a contradiction to the describable feature itself. In this case, overcoming the paradox consists in the ban on confusing in one object a feature and its description presented as a feature.

The paradox of the least indefinable ordinal is similar to Berry's Paradox, namely, an ordinal is discussed that has feature S1 and feature S2, and S2 is the description of S1.

In Richard's Paradox there is a situation analogous to Berry's Paradox and to the paradox of the least indefinable ordinal (Russell 1908: 224-225).

\section{ARGUMENTS CRITICAL OF THE HIERARCHICAL APPROACH TO SOLVING LOGICAL PARA- DOXES}

Arguments critical of formulating the hierarchical approach were expressed by thinkers at various times and in various contexts. The criticisms may be classified in the following way:

First, in the opinion of some thinkers, the ban on self-reference harms research possibilities in logic, mathematics and philosophy. Thus, Anderson points out, 'The difficulty with such a stance is that some of the most profound arguments in logic involve self-reference (in 
some sense that needs to be made precise)' (Anderson 1970: 8). Fitch agrees, pointing out that the theory of types must at least be restricted:

"The problem is to find a theory of types which eliminates the "vicious" sorts of self-reference that lead to the mathematical and semantical paradoxes but not those sorts of self-reference that seem to be such an important part of philosophical logic, or required in developing the theory of numbers' (Fitch 1946: 71-72).

Kripke notes that Gedel's theorems include self-reference. By this reasoning, he asserts that a full ban on self-reference harms important mathematical achievements (Kripke 1975). Finally, Fitch asserts that self-reference is an important idea for philosophy, not only for logic and mathematics. In his view, philosophy as a maximally broad representation of being must rest on self-reference to obtain the most complete knowledge: 'It is characteristic of philosophy to reach this maximum level and to be able to use the self-referential sorts of reasoning which are possible on this level' (Fitch 1946: 69).

Second, a group of critics of the hierarchical approach places attention on the fact that some forms of self-reference do not lead to paradoxes. One can see that only the negative self-reference leads to paradoxes, whereas the positive self-reference does not. Thus, Bolander differentiates the concepts of vicious self-reference and innocuous self-reference: 'Self-reference that leads to paradoxes we call vicious self-reference and self-reference that does not we call innocuous self-reference' (Bolander 2002: 24). Beall (2001) uses the concept 'truth-teller' for describing a self-referential statement with a predicate of truth but without negation. This example is demonstrative, because if we substitute the predicate of truth with negation for the predicate of truth without negation in formulation of the Liar Paradox, then the paradox immediately disappears. Bolander gives attention to this fact too: 'It can be shown that self-reference can only be vicious if it involves negation or something equivalent' (Bolander 2002: 24). Thus, one can conclude that self-reference as such is not the main cause of paradoxes, for there are examples of self-reference that do not lead to paradoxes. Russell's and Tarski's hierarchical approach appears unreasonable and too radical. It forbids quite consistent forms of self-reference with forms that lead to paradoxes.

Third, the hierarchical approach generates 'revenge problems' (Field 2003), situations in which some solutions of paradoxes appear as paradoxical themselves, that is, they are ensnared by the paradoxes that they try to overcome.

Weiss was one of the first critics of the theory of types. Yet, at the end of the 1920s, he published an article in which he pointed to problems in Russell's conception (Weiss 1928). Russell's theory of types bans universal discourse as a whole: it is impossible to speak about all things by one concrete statement. Each concrete statement may speak about only a limited subject area. Therefore, the truth value of the statement cannot be universal either; it should be relativized concerning the specific subject matter presented in the statement. But what about the formulation of the theory of types itself? Either the theory presents only a specific type of statements for a specific subject area, or it is an example of universal discourse about the totality of statements. If it presents only a specific type of statement, then it admits statements of different types that were produced on the foundation of principles other than the principle of the theory of types. Thus, the theory of types should admit its own negation. If the theory is an example of universal discourse about the totality of statements, then the form of affirmation of the theory contradicts its content: the thesis about impossibility of universal statements is formulated in the statement claiming the status of a universal statement. As a result, the theory of types itself is paradoxical. 
Fitch notes that Russell's ramified theory of types can be built only on the precondition of the existence of a universal self-referential conception that was banned by the theory. If this precondition is excluded, then the theory of types cannot be developed. Having criticized the ramified theory of types, Fitch asserts:

'For example, the ramified theory of types cannot assign a type to the meaning of the word "type", and yet it must do so if the theory applies to all meanings. In a similar way, no "order" (in the sense used in the ramified theory of types) can be assigned to a proposition which is about all propositions, hence no order can be assigned to the proposition which states the ramified theory of types' (Fitch 1946: 71).

Putnam's argument about Red Ink Language works very well against Tarski's semantic conception (Putnam 1990). Suppose that sentences of different languages are written in inks of all known colours excluding red. Red ink is used for the rules of construction of sentences for all the languages. If rules for all languages are written in red ink, then we put the question: what is the colour for the notation of rules for the Red Ink Language (i.e. for Tarski's semantic conception)? If the answer is 'red', then the Red Ink Language is closed on itself, that is, it is a self-referential language. If we suppose inks of some other unknown colour, then rules that are written in red ink for all known languages cannot be used for this new language, and the sentences written with new, unknown inks should be formulated on the basis of other rules.

Fourth, having criticized the hierarchical approach, some thinkers base their conclusion on the common sense. It is asserted that the hierarchical approach simply does not correspond to the common sense that it is counterintuitive. For example, Martin says, 'My point, so far, is only that the question of a natural language's ability to express its own semantics is an important one, to which the currently orthodox answer is, to a striking degree, counter-intuitive' (Martin 1976: 272). The hierarchical approach is counterintuitive and so trivial. Martin continues:

'Of course giving up the means of self-reference makes it possible to include a truth predicate or satisfaction predicate with impunity, but this is by no means the only way, and it is certainly not the most natural or interesting way' (Martin 1976: 275).

Martin's critical arguments may first be illustrated by epistemological problems. If an epistemologist produces a statement about the truth of theoretical statements in general, then in the hierarchical approach it is forbidden to put a question about the truth of this statement itself in the same sense in which the epistemologist speaks about the truth of theoretical statements. This ban appears at least as strange from a common sense point of view. How may we consider the theses of the epistemologist about the truth of theoretical statements seriously if his or her own epistemological theory consisting of statements of this kind cannot be guided by the theses that are formulated in this theory? Is the epistemologist able to say something reliable about other theoretical statements if he or she cannot say something reliable even about his or her own theoretical statements? But it would be so primitive and trivial to try to resolve the question by a method (i.e. the hierarchical approach) that allows the epistemologists to ignore the question.

\section{THE SPECIAL PLACE OF WITTGENSTEIN'S POSITION IN THE HIERARCHICAL APPROACH TO THE SOLUTION OF LOGICAL PARADOXES}

In discussion around the hierarchical approach to the solution of logical paradoxes, one can draw attention to Wittgenstein's position. He adopts the idea of the hierarchy of logical levels of statements and thus is a proponent of the hierarchical approach. But in one important point his position differs from Russell's and Tarski's views. The position is expressed in Tractatus Logico-Philosophicus, paragraphs 333.2 and 333.3: 
333.2. No proposition can say anything about itself, because the propositional sign cannot be contained in itself (that is the 'whole theory of types').

333.3. A function cannot be its own argument, because the functional sign already contains the prototype of its own argument and it cannot contain itself.

If, for example, we suppose that the function $F(f x)$ could be its own argument, then there would be a proposition ' $F(F(f x))$ ', and in this the outer function $F$ and the inner function $F$ must have different meanings; for the inner has the form $\phi(f x)$, and the outer has the form $\psi(\phi(f x))$. Common to both functions is only the letter ' $F$ ', which by itself signifies nothing.

This is at once clear if instead of ' $F(F(u))$ ' we write ' $(\exists \phi): F(\phi u) . \phi u=F u$ '.

Herewith Russell's paradox vanishes (Wittgenstein 1922).

The point is that Russell's theory of types and Tarski's semantic conception are artificial methodological steps to correct defects of natural (everyday) languages. Tarski thought that natural languages are semantically closed, universal languages in which the phenomenon of self-reference is allowed. These languages are defective because paradoxes may appear in them:

'But it is presumably just this universality of everyday language which is the primary source of all semantical antinomies, like the antinomies of the liar or heterological words. These antinomies seem to provide a proof that every language which is universal in the above sense, and for which the normal laws of logic hold, must be inconsistent' (Tarski 1956: 164-165).

Tarski supposes that the solution of the problem of paradoxes (antinomies) consists in building artificial logical languages in which the phenomenon of self-reference is excluded. Russell's position is similar: only artificial logical languages that are 'vaccinated' against paradoxes by means of the theory of types will be consistent.

Therefore, insofar as Russell's theory of types and Tarski's semantic conception are artificial methodological techniques, some vaccinations for natural languages, we can discuss the question about the necessity to use them. Many scholars do not agree that vaccinations for natural languages are necessary. Some doubt that the 'injections' are needed even for artificial languages, for example, mathematical languages.

But Wittgenstein's position is different in essence. He asserts that the hierarchy is not entered into language as some artificial methodological project for improving it. The language takes care of itself. The hierarchy of logical types is an intrinsic feature of the language. Our task is only to recognize the hierarchy, and in this sense Wittgenstein says in paragraph 333.2: 'that is the "whole theory of types" (Wittgenstein 1922). This remark by Wittgenstein means that the theory of types is correct but that it is useless. We do not need it. The theory of types does not enter the hierarchy into the language; the hierarchy is already contained in it.

If Wittgenstein is right, discussion of the relevance of Russell and Tarski's hierarchical approach to the solution of logical paradoxes appears superfluous. We do not have a choice to accept the hierarchy or not: the hierarchy is inherent in the language by the nature of the language, independent of our opinions about the question.

\section{CONCLUSIONS}

Wittgenstein's position expressed in paragraphs 333.2 and 333.3 of Tractatus Logico-Philosophicus is the most steadfast form of the hierarchical approach to the solution of logical paradoxes in the relation to critical arguments that were expressed in research literature on logic, epistemology, and the philosophy of mathematics in the last several decades. 
One can think that the hierarchy of types of statements in the language in which self-referential forms of reasoning are excluded harms the development of logic, mathematics and philosophy. One can think that the hierarchy does not correspond to the common sense. But the point is that this hierarchy is not an invention of Russell or Tarski. It is not an artifact created by a human being at all. The hierarchy reflects the essence of language, and we should take it as such. Moreover, denoting the hierarchy in language does not generate revenge problems, because it is not done in a form of some theoretical conception in relation to which these revenge problems would be formulated.

If we still want to demonstrate that the hierarchical approach is a valid, acceptable way to solve the problem of paradoxes, we should employ its Wittgensteinian interpretation, because it is able to overcome the serious critical arguments presented above.

\section{ACKNOWLEDGEMENTS}

The study was supported by the Russian Science Foundation (Research Project 18-18-00057). I am indebted to Jean Kollantai for assistance with stylistic editing.

\section{References}

1. Anderson, A. P. 1970 "St. Paul's Epistle to Titus", in The Paradox of the Liar, ed. R. L. Martin. New Haven and London, 1-11.

2. Beall, Jc. 2001. "A Neglected Deflationist Approach to the Liar", Analysis 61(2): 126-129.

3. Bolander, T. 2002. "Self-reference and Logic", ФNews 1: 9-43.

4. Field, H. 2003. "A Revenge-immune Solution to the Semantic Paradoxes", Journal of Philosophical Logic 32: 139-177.

5. Fitch, F. 1946. "Self-reference in Philosophy", Mind 55(217): 64-73.

6. Kripke, S. 1975. "Outline of a Theory of Truth", The Journal of Philosophy 72(19): 690-716.

7. Martin, R. 1976. "Are Natural Languages Universal?", Synthese 32(3/4): 271-291.

8. Putnam, H. 1990. Realism With a Human Face, ed. J. Conant. Cambridge, Massachusetts: Harvard University Press.

9. Russell, B. 1908. "Mathematical Logic as Based on the Theory of Types", American Journal of Mathematics 30(3): 222-262.

10. Sainsbury, R. M. 2009. Paradoxes. 3rd edn. Cambridge: Cambridge University Press.

11. Surovtsev, V. 2016. "To lekton in Stoic Philosophy and Sinn in G. Frege's Semantic Theory:

The Question of Their Ontological Status", Schole. Ancient Philosophy and the Classical Tradition 10(2): 452-470.

12. Tarski, A. 1935. "Der Wahrheitsbegriff in den formalisierten Sprachen", Studia Philosophica 1: 261-405.

13. Tarski, A. 1956. “The Concept of Truth in Formalized Languages”, transl. by J. H. Woodger, in Logic, Semantics, Metamathematics, ed. J. H. Woodger. Oxford: Oxford University Press, 152-278.

14. Tselitschev, V. 2014. "Platonism in Mathematics", Schole. Ancient Philosophy and the Classical Tradition 8(2): 492-504.

15. Weiss, P. 1928. “The Theory of Types", Mind 37(147): 338-348.

16. Wittgenstein, L. 1921. "Logisch-philosophische Abhandlung", Annalen der Naturphilosophie Band 14: $185-262$.

17. Wittgenstein, L. 1922. Tractatus Logico-Philosophicus. Transl. by C. K. Ogden. London: Kegan Paul, Trench, Trubner \& Co., Ltd. 
VSEVOLOD LADOV

\title{
L. Wittgensteino Tractatus Logico-Philosophicus ir hierarchinis požiūris sprendžiant loginius paradoksus
}

\author{
Santrauka \\ Straipsnyje kritikuojamas hierarchinis požiūris nagrinëjant loginius paradoksus. Hie- \\ rarchinio vertinimo pagrindai ir esminès tezès remiasi B. Russello tipų teorija ir \\ A. Tarskio semantine samprata. Straipsnyje šis požiūris, suformuluotas loginiame ir \\ epistemologiniame tyrime, kritikuojamas. Nustatoma specifinè L. Wittgensteino po- \\ zicija hierarchinio suvokimo požiūriu. Ji pateikta veikale Tractatus Logico-Philosophicus. \\ Filosofo hierarchinio traktavimo versija nagrinejama kaip priimtiniausia. Jei norime \\ vertinti hierarchinị suvokimą kaip priimtiną loginių paradoksų problemos sprendimą, \\ turettume taikyti L. Wittgensteino interpretaciją, nes ji geba ịveikti rimtus kritinius ar- \\ gumentus, pateiktus šiuolaikiniuose logikos, epistemologijos ir matematikos filosofijos \\ tyrimuose.
}

Raktažodžiai: paradoksai, matematikos filosofija, semantika, tipų teorija, kalba, metakalba, nuoroda ị save, hierarchinis suvokimas 